Article

\title{
Overview of the Nuclear Fuel Cycle Strategies and the Spent Nuclear Fuel Management Technologies in Taiwan
}

\author{
Tsuey-Lin Tsai ${ }^{1, *}$, Yi-Fu Chiou ${ }^{2}$ and Shih-Chin Tsai ${ }^{3}$ \\ 1 Chemistry Division, Institute of Nuclear Energy Research, Atomic Energy Council, Taoyuan 32546, Taiwan \\ 2 Health Physics Division, Institute of Nuclear Energy Research, Atomic Energy Council, \\ Taoyuan 32546, Taiwan; yfchiu@iner.gov.tw \\ 3 Nuclear Science and Technology Development Center, National Tsing Hua University, \\ Hsin-Chu 30013, Taiwan; sctsai@mx.nthu.edu.tw \\ * Correspondence: polly@iner.gov.tw; Tel.: +886-3-471-1400 (ext. 5028)
}

Received: 8 May 2020; Accepted: 8 June 2020; Published: 10 June 2020

\begin{abstract}
The continued use of nuclear energy has come into question due to the difficulties in managing radioactive waste, and public opposition has increased since the Fukushima nuclear disaster in March 2011. Nonetheless, the novel spent nuclear fuel (SNF) management technologies proposed indicate new pathways toward facilitating the environment and the sustained use of nuclear energy. The reprocessing and recycling of SNF provides an alternative to direct geological disposal. In this article, we examine the current status and strategic alternatives of radioactive waste management in Taiwan.
\end{abstract}

Keywords: nuclear energy; spent nuclear fuel (SNF); radioactive waste management; reprocessing; final disposal

\section{Introduction}

Energy perspectives all over the world are dominated by the anticipated increase of its demand due to population growth and economic activities of emerging countries. In addition, industrialization by human activities in the developing or developed countries has partially proved the relationship with global climate change resulting from the release of greenhouse gases (GHG) [1]. The latest data showed that the global energy demand and energy-related $\mathrm{CO}_{2}$ emissions from FY 1900 to Q1 2020 have gradually increased over the past decades except for the significant events (e.g., great depression, World War II, financial crisis and impact of COVID-19) [2]. We need to face a challenging issue in the future: the increase of the energy demand with a decrease of GHG emissions, as the fossil fuels are dominating about $80 \%$ of primary energy.

Nuclear power has demonstrated over the past 40 years its enormous capacity to supply stable and reliable base-load electricity on a large scale and low carbon emission. Therefore, nuclear energy can remarkably contribute to the energy security of countries [3]. In general, the global nuclear energy's share of total electricity generation continues slowly but steadily declines from the highest $17.5 \%$ in 1996 to $10.15 \%$ in 2018 [4]. The nuclear electricity production grew for a sixth consecutive year due to new reactors being commissioned in China. Four nuclear reactors are gradually being restarted to reduce $\mathrm{CO}_{2}$ emissions in Japan for a post Fukushima energy policy despite anti-nuclear sentiment. Switzerland restarted the oldest nuclear power plant in March 2018 after a three-year shutdown for repairs to supply reliable electricity regardless of anti-nuclear protests [4-6]. However, safety concerns have been raised by the Fukushima Daiichi accident in 2011. Proponents of nuclear energy cite the availability of fuel, the potential to mitigate global warming, and stability that cannot be matched 
by solar or thermal energy [7]. Opponents of nuclear energy cite safety concerns, the proliferation risk, high capital investment, and the problem of managing radioactive waste. Regardless of nuclear energy in the future, SNF management is an issue that must be resolved in every country that produces nuclear waste. Furthermore, this issue must be addressed properly because the time frames are quite long and imposes a burden on future generations. [8,9]

The current government of Taiwan (elected in January 2016 and 2020) has adopted the energy policy of attaining a nuclear-free homeland by 2025 by steadily reducing the dependence on nuclear power and moving steadily towards a nuclear-free homeland. Each of the operating nuclear power plants will be decommissioned when its 40-year operating license expires. In addition, the power generation will be focused on the development of environment-friendly low-carbon and green energy in the future [10]. As shown in Table 1 [11], there are four operating nuclear power reactors (two boiling water reactor (BWRs) and two pressurized water reactor (PWRs)) installed between 1981 and 1985 , which account for approximately $15 \%$ of the electricity generation in Taiwan. Only two units of advanced boiling water reactors (ABWR) with each of them generating $1300 \mathrm{MWe}$ had ever been recorded as "under construction" at Lungmen of New Taipei City, since 1998 and 1999. The anticipated completion year of construction was 2004 for the Lungmen nuclear power plant, indicating they were installed more than 20 years ago. The status of unit 1 was up to $95 \%$ completed and both of the two units were deferred for commissioning. The project was significantly delayed and the plant has been mothballed after experiencing legal, regulatory and political issues. The process to restart the plant would also take much time, as it would involve reallocating budgets in the legislature, renewing a license application to the regulatory body (AEC; atomic energy council) to end the suspension, and performing follow up tests and examinations. On the other hand, public opinion of nuclear energy changed dramatically following the Fukushima accident. In 2014, 55\% favored dropping Lungmen, and 35\% agreed with mothballing it [11]. Moreover, on 1 February 2019, Taiwan Power Company (TPC), the owner of utility, ruled out any possibilities for the operation of the two units of Lungmen nuclear reactors and there will be no life extension or restoring of nuclear power plants in Taiwan in any case.

Table 1. Taiwan nuclear power reactors. Reproduced from [11], World Nuclear Association, 2019.

\begin{tabular}{ccccccc}
\hline Units & Type & MWe Gross & MWe Net & Start Up & Licenced Till & Permanent Shutdown \\
\hline Kuosheng 1 & \multirow{2}{*}{ BWR-6 } & 985 & 948 & 1981 & December 2021 & \\
Kuosheng 2 & 985 & 948 & 1983 & March 2023 & \\
Maanshan 1 & \multirow{2}{*}{ PWR } & 951 & 900 & 1984 & July 2024 & \\
Maanshan 2 & & 951 & 923 & 1985 & May 2025 & \\
Total (4) & & 636 & 604 & 1978 & December 2018 & October 2018 \\
Chinshan 1 & \multirow{2}{*}{ BWR-4 } & 636 & 604 & 1979 & July 2019 & July 2019 \\
Chinshan 2 & & 636 & \multicolumn{5}{c}{} \\
\hline
\end{tabular}

Under the policy of nuclear-free homeland by 2025, decommissioning of nuclear power plants shall adopt an immediate dismantlement method and the decommissioning work shall be completed within 25 years upon obtaining the decommissioning permit. As shown in Table 2 [12], the cooling pools at the Chinshan nuclear power plant (NPP1) and Kuosheng nuclear power plant (NPP2) are nearly filled to capacity with spent fuel assemblies. Under these conditions, nuclear reactors cannot be refueled and must therefore cease operations.

A proposal to send SNF from the NPP1 overseas for small-scale reprocessing in 2015 to relieve fuel pool space has been pending because the budget was rejected by the congress. An interim on-site dry storage facility at NPP1 has also been put on hold by the water and soil conservation division of the local government in response to protests by anti-nuclear groups and environmental protection organizations. Nonetheless, this problem is political-not technical. Geological assessments (host rock characterization and evaluation) have been conducted since 2015 to identify suitable regions for final repository. 
Our aim in this paper was to elucidate the major strategies for the nuclear fuel cycle, the interim storage and final disposal of SNF. Thus, the understanding of technical readiness and challenges can help find a practical way in the future.

Table 2. Inventories of spent nuclear fuel (updated to the end of March 2020). Reproduced from [12], Atomic Energy Council, Taiwan, 2020.

\begin{tabular}{|c|c|c|c|}
\hline \multirow{2}{*}{ Units } & \multirow{2}{*}{$\begin{array}{l}\text { Storage Capacity } \\
\text { (Assembly) }\end{array}$} & \multicolumn{2}{|c|}{ Storage Inventory } \\
\hline & & Fuel Assembly & Mass of Uranium (MtU) \\
\hline Chinshan 1 & $3083 *$ & 3074 & 528 \\
\hline Chinshan 2 & 3083 * & 3076 & 529 \\
\hline Kuosheng 1 & 4838 & 4808 & 808 \\
\hline Kuosheng 2 & 4838 & 4540 & 763 \\
\hline Maanshan 1 & 2160 & 1581 & 631 \\
\hline Maanshan 2 & 2160 & 1528 & 610 \\
\hline Total & 20,162 & 18,607 & 3869 \\
\hline
\end{tabular}

* The regulatory authority (AEC) approved an increase in the storage capacity of Chinshan units 1 and 2 to load 440 spent fuel bundles in May 2017 and January 2019, respectively.

\section{Major Strategies for the Nuclear Fuel Cycle}

The nuclear fuel cycle includes all of the steps and processes through which nuclear fuel passes before and after being used in an NPP for the generation of electricity. This can be divided into two main stages: (1) front-end including all activities from uranium ore to fuel use inside the reactor and ending when the fuel is loaded in the reactor and (2) back-end starting when fuel leaves the reactor and all activities until final disposal.

There are two major strategies: the open cycle (or direct disposal) and closed cycle (cycle with reprocessing). The former includes two back-end stages: interim storage and final disposal. First of all, SNF is discharged from the reactor to undergo cooling in reactor pools [13]. SNF becomes cooler and less reactive when stored in a cooling pool to remove decay heat and radiation, indicating that SNF removed from the reactor core and placed into cooling pools would increase safety. However, it would be much safer when SNF removed from the cooling pools and transferred into dry cask storage, which were developed and implemented with existing technologies [13-16].

\section{Reprocessing in Taiwan}

The reprocessing of SNF for permanent disposal reduces the volume by around $80 \%$, in comparison with the disposal of entire fuel assemblies. It can also be used to recover uranium and plutonium, the major actinides for recycling. Therefore, high-level waste (HLW) is considered as a type of radioactive waste generated by the reprocessing of SNF. In Britain and France, reprocessing is also used to deal with fuel from Italy, Japan, Switzerland, Germany, and the Netherlands.

Taiwan has forever been contemplating reprocessing existing SNF as a means to extend the spent fuel storage capacity at the reactor sites. As mentioned above, the wet storage pools are near capacity, and there is no option to expand SNF storage, either wet or dry, due to political or technical constraints. The current policy for SNF management is long-term storage and then direct disposal. Although the reprocessing method is not officially the main policy, the SNF reprocessed through the international cooperation is acceptable if it is necessary $[17,18]$.

A tender for overseas reprocessing of SNF was suspended in March 2015, pending a parliamentary budget review. Nonetheless, the Taiwan Power Company (TPC) is seeking to promote the idea of overseas reprocessing by implementing a small-scale trial. It is expected that this scheme could enhance flexibility in the development of a domestic strategy for the long-term management of SNF. 


\section{Interim Storage}

As of September 2014, 16,852 fuel assemblies (3471 tons) were being held in spent fuel pools at the three Taiwanese plants. As of 2015, the spent fuel pools at Chinshan and Kuosheng were nearly full. Therefore, interim storage was the first stage for the back end of the open fuel cycle. To safely store and continuously monitor SNF is the goal until enough heat has been removed for final disposal.

\subsection{Dry Storage}

Approximately $\frac{1}{4}$ to $1 / 3$ of the nuclear fuels in a reactor core will be periodically discharged and replaced with fresh fuels at the end of cycle (EOC). The unloaded fuel, also known as "spent fuel" must be temporarily stored in a water pool adjacent to the reactor.

The spent fuel assemblies are generally organized in a checkerboard pattern with a hot (newer) spent fuel assembly surrounded by four cold (older) assemblies. The sufficient safety-related instrumentation to enable the monitoring of pool parameters should be provided from the main control room. After several years of storage, residual heat within the fuel has dropped sufficiently to allow the transfer of the spent fuel into dry casks for extended storage. Dry cask storage has inherent advantages over wet storage in a spent fuel pool; however, it is applicable only to older spent fuel.

\subsection{On-Site Dry Storage Technologies}

TPC has begun looking at the storage of SNF in a dry storage facility, named as an independent spent fuel storage installation (ISFSI). An ISFSI pad, shown in Figure 1 [19] is utilized to bear the weight of vertical concrete casks (VCC) and add-on shields (AOS) at the Chinsan nuclear power plant. This program was originally moving ahead with the construction of an on-site ISFSI as a medium-term solution for Taiwan and the critical safety issues and confirmatory evaluations have been identified.

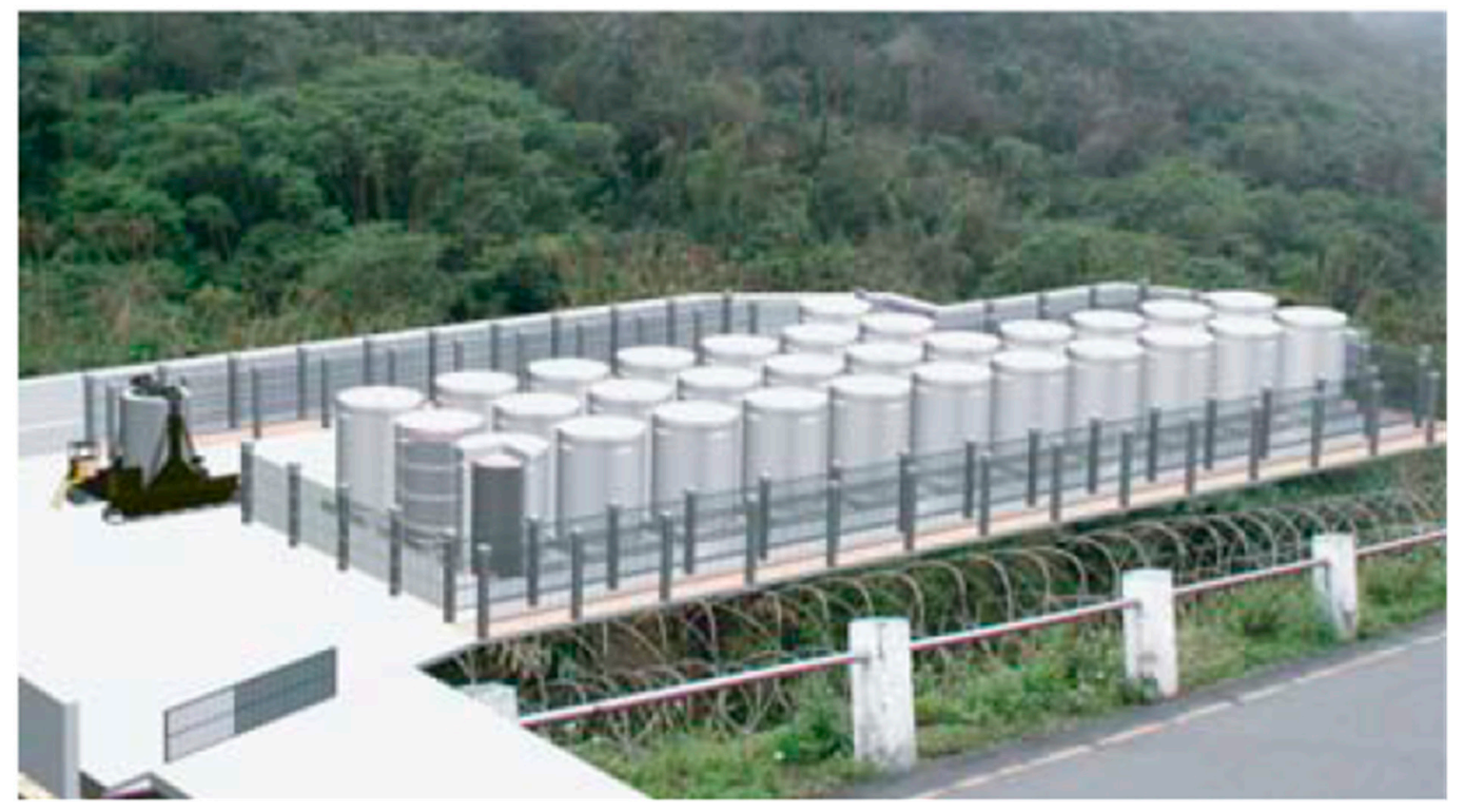

Figure 1. Layout of the independent spent fuel storage installation (ISFSI) pad at Chinshan nuclear power plant (NPP). Reproduced from [19], Wiley Online Library: New York, NY, USA, 2013.

ISFSIs are located within the site of an existing nuclear power plant; however, each canister is encased in added steel, concrete, or other materials for further radiation protection [20]. These measures are meant to ensure that the annual effective dose does not exceed $0.25 \mathrm{mSv}$ at the site-specific boundary distance $(>100 \mathrm{~m}$ ) of spent fuel dry storage (ISFSI) and the annual effective dose does not exceed $0.5 \mathrm{mSv}$ at site boundary of the nuclear power plant. 
TPC has entrusted the Institute of Nuclear Energy Research (INER) to establish a dry storage facility at NPP1 using the US NAC-UMS system. They have also been contracted for the Kuosheng site using NAC Magnastor system to deal with 27 casks each holding 87 fuel assemblies for a total of 2349 assemblies. Although the foreign technical consultations were required and technology was transferred from NAC International, INER still modified some original designs, in particular, the crucial safety aspects for, such as development of the component of add-on shields (AOS) for radiation protection, structural performance of seismic impact, decay heat removal function and confinement integrity of concrete cask of the storage system, which was named as INER-high performance system (INER-HPS) in order to meet the site-specific conditions. The aforementioned critical safety issues were also involved in the review program by AEC.

The simplified diagrams in Figure 2 [19] illustrate the four main components of the INER-HPS storage system, including a transportable storage canister (TSC), a transfer cask (TFR), a vertical concrete cask (VCC) and add-on shielding (AOS). Canister (TSC), typically a welded or bolted closed steel cylinder providing leak-tight confinement, is composed of a canister (stainless steel) shell, bottom plate, shield lid and structural lid. The fuel basket that is used to place or support the SNF surrounded by inert gas, vent hoses and a drain/blow down system is also within a TSC. TSC is used to accommodate 56 BWR SNF assemblies and is designed to be loaded, sealed and handled in a transfer cask (TFR) for dry storage systems. The transfer cask, a heavy hanging equipment with shielding function, is utilized to move the TSC in and out of the SNF pool for fuel loading and to be stacked on top of a VCC for transferring a TSC into VCC. AOS is installed to enhance radiation shielding.
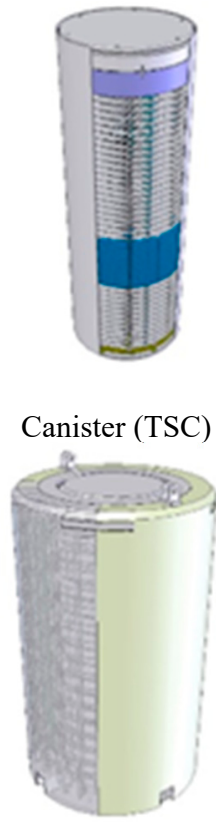

Concrete Cask (VCC)
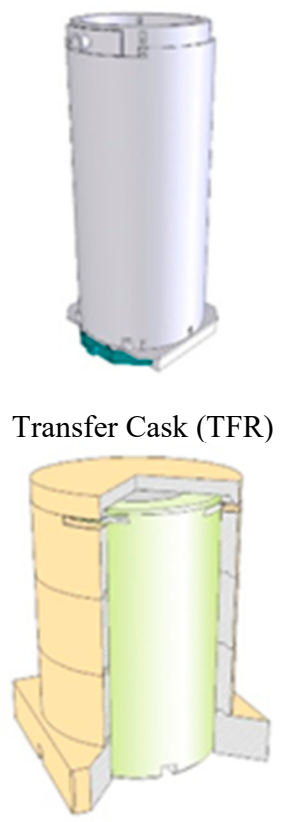

Add-on Shield (AOS)

Figure 2. Main components of the Institute of Nuclear Energy Research-high performance system (INER-HPS) storage system. Reproduced from [19], Wiley Online Library: New York, NY, USA, 2013.

The outer diameters of the canister and concrete cask are 1.70 and $3.45 \mathrm{~m}$, respectively. The AOS looks like the cylindrical cover of a CD-shaped disc spindle. It can be decomposed into several cylindrical segments with a donut-shape. When the VCC is put in, the AOS components are assembled one-by-one. Therefore, the dry storage is a mature and safe technique. 


\subsection{Current Status}

The construction of the phase I dry storage facility at Chinshan (ISFSI project) was completed in 2013 after AEC issued the license in December, 2008. TPC has already achieved the first stage of the pre-operational test and this cold test report was also approved by AEC in Sept. 2013. AEC also approved that TPC would perform the second stage of pre-operational test (also called the hot test). However, the New Taipei City government strongly opposed issuing a permit for a water and soil conservation plan (WSCP) of the facility, as the local government refused to allow dry-cask storage within its boundaries. This means that the SNF will not be stored permanently in New Taipei City, unless TPC can propose a solid plan for site selection of final disposal for SNF. Nevertheless, to this date, the permanent storage of SNF has been a global issue and a site for final disposal has not been selected yet at this stage. As a result, SNF currently stored in the pool cannot be moved to dry storage and the storage pool has almost reached maximum capacity. Subsequently, the SNF must be temporarily stored in a reactor and TPC cannot commence the second pre-operational hot test until receiving approval from the local government, which makes the situation into a dilemma.

The construction license of Kuosheng dry storage facility by AEC was issued in August 2015, at which point there were 8616 fuel assemblies in the spent fuel ponds (1449 tons). However, other forms of approval for this storage site have also been rejected by the New Taipei City government, which is the same situation with the dry storage facility at Chinshan. As a result, TPC had to shut down the reactor in November 2016, as it was not able to proceed with refueling due to no place to store the SNF. Chinshan 2 temporarily ceased operations in May 2017, owing to lack of storage space in the SNF pool. In April 2017, the AEC approved TPC's application to convert the cask loading pool at Kuosheng 1 into a fuel storage site, however, it has been suspended by the local government [11]. TPC has been actively continuing to communicate with the local government and residents. On the other hand, TPC initiated the feasibility studies on centralized interim storage as an alternative option, as it was difficult to select a site for the final repository. The contingency plan for a centralized interim storage facility with enough capacity will temporarily store the different types of radioactive waste, including low-level and high-level radwastes from routine operation and decommissioning tasks of the nuclear power plants. This interim approach of integrated waste management encompasses a period of about 40-100 years; a target of 40 years of operation and a design criteria of 100 years. Based on the existing regulations, the centralized interim storage is a transitional stage and will follow the Act to design and be approved by a regulatory body without the need of passing the local referendum [21].

\section{Final Disposal}

\subsection{Fundamental Principles and Regulatory Framework}

Direct disposal refers to the transfer of SNF, following a period for 40-60 years of dry storage, to a permanent disposal site where it will remain for hundreds of thousands of years till its radiotoxicity reaches that of the natural uranium level (i.e., the safe reference level).

The safe disposal of SNF or HLW is the biggest hurdle in the nuclear energy industry. Taiwan is currently dealing with the need to manage it from three nuclear power plants.

There is a strong international consensus that geological repositories for the disposal of SNF or HLW provides the highest level of protection with respect to public health and the environment [22]. As in Sweden, Finland, Japan, and France, authorities in Taiwan have embraced the notion of using geological sites for the disposal of SNF or HLW. In 2004, TPC initiated a study on the long-term deep geological disposal of SNF to begin operation in 2055. Figure 3 [23] presents the milestones in the Taiwanese SNF disposal (SNFD) five-stage program. This program is currently in the "Selection and determination of potential sites" (2017-2028) and the search for specific sites needs to be initiated. In 2017, the "Technical feasibility assessment report on spent fuel final disposal" has been completed after an international peer review. This paper will outline the technical capabilities required for the final disposal of SNF. 


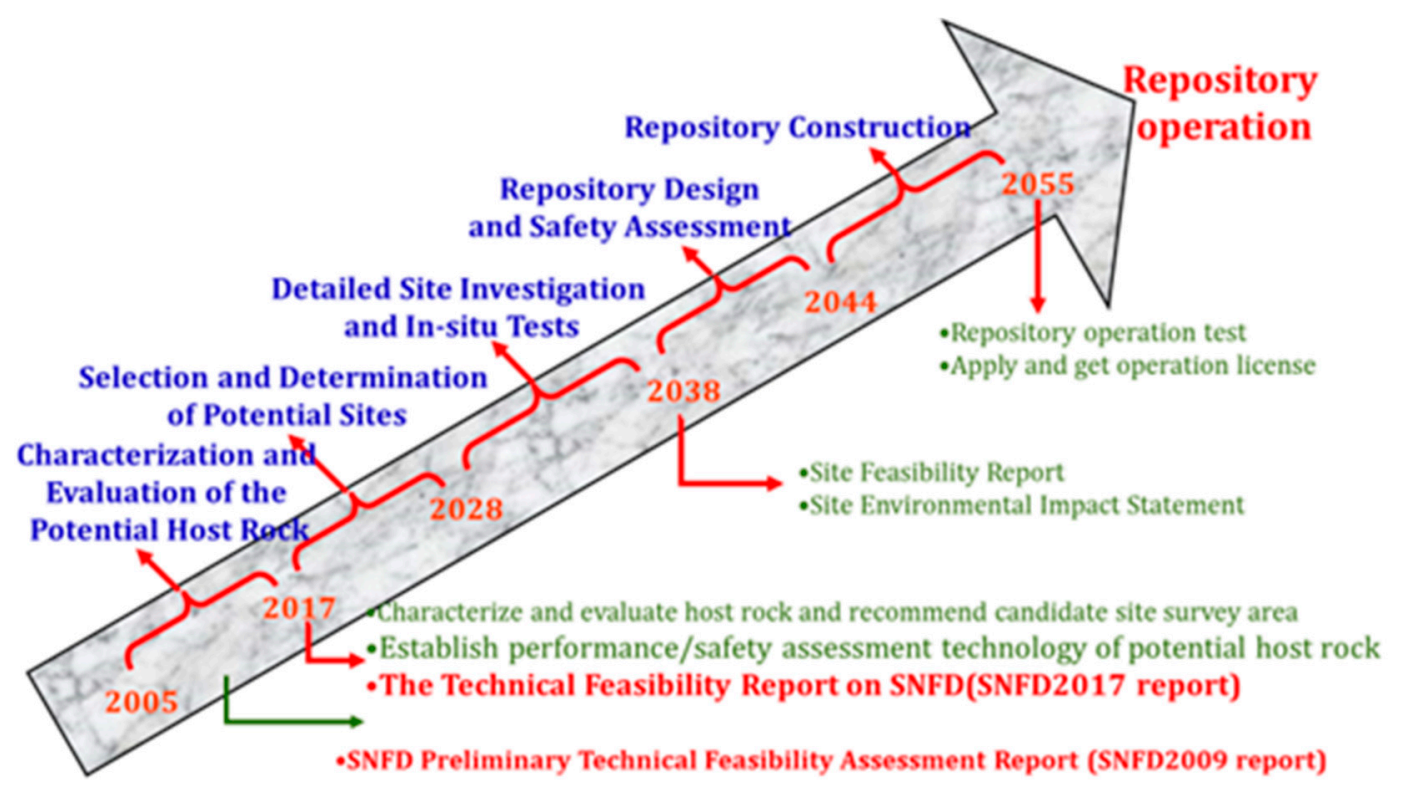

Figure 3. Stages of SNF disposal (SNFD) program in Taiwan. Reproduced from [23], Taiwan Power Company: Taipei, Taiwan, 2019.

\subsection{RED Activities and Plan of Action}

In the "Characterization and evaluation of potential host rock" for the period 2005-2017, the primary objective was to conduct a feasibility study to achieve the goal that is to prove the readiness of a geological survey, engineering design and safety assessment with the kärnbränslesäkerhet, nuclear fuel safety (KBS-3) disposal concept. The KBS-3 system is a multiple barrier concept [24]. The Swedish and Finnish spent nuclear fuel and waste management companies, SKB (Svensk Kärnbränslehantering Aktiebolag) and Posiva Oy, approach to spent fuel disposal is also based on this conceptual design, wherein SNFs are held within corrosion-resistant copper canisters with a cast-iron insert. The copper containers are surrounded by bentonite used as buffer material and placed in granite bedrock at a depth of approximately 500 meters. The main elements of the KBS-3 (an abbreviation of kärnbränslesäkerhet, nuclear fuel safety) concept, which is a technology for final disposal of SNF developed in Sweden by SKB, are presented in Figure 4 [24].
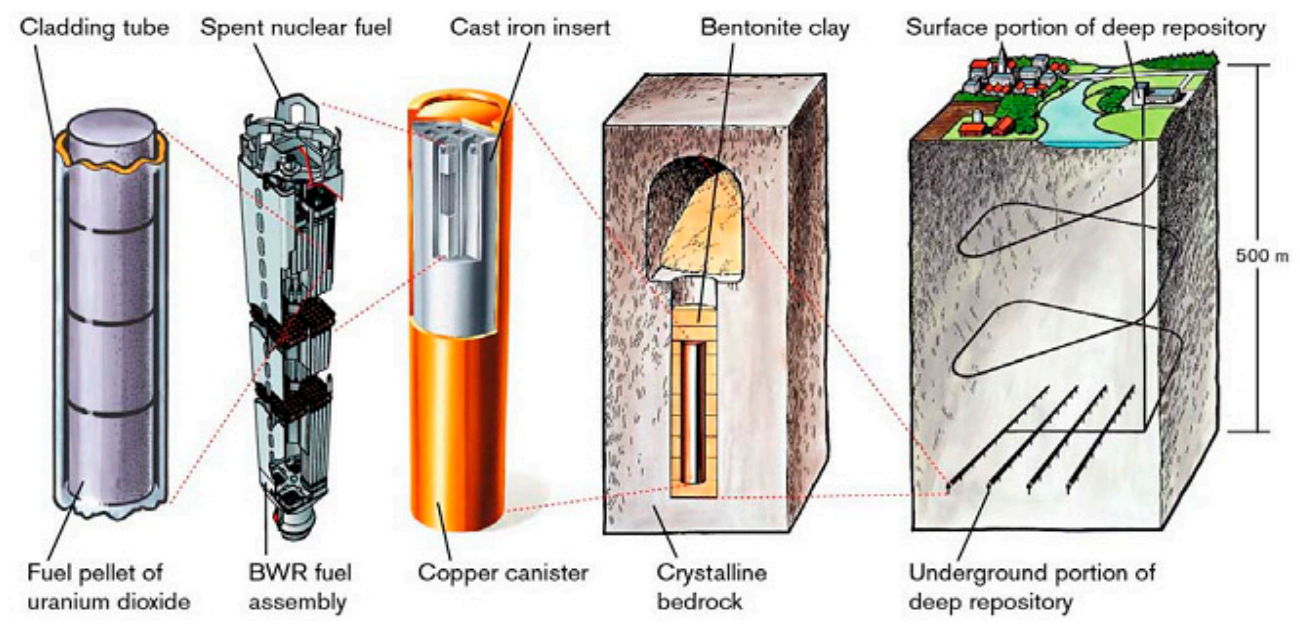

Figure 4. Barrier system used in deep repositories for spent nuclear fuel. Reproduced from [24] Svensk Kärnbränslehantering AB: Stockholm, Sweden, 2011. 
The SNFD research team of TPC has conducted site investigations (site description models, hydrogeology, and groundwater geochemistry), safety assessments (assessment model chain, safety function and related indicators, and uncertainty analysis), engineering design (mockup engineering barrier, T-H-M-C coupling experiment, modeling, and conceptual design of repository) and supporting research activities (e.g., reference evolution, radionuclide transport, biosphere dose modeling, and natural analogs). Engineers must also make it possible to retrieve the SNF if advanced technologies become commercially available in the future.

Underground research laboratories (URL) will be constructed in 2033 to demonstrate the technical feasibility of the program [23]. The studying activities of generic and site specific URL at crystalline rock test areas will be useful for the further safety case investigation. No radioactive substances will be used in the URL or released from it.

A number of R\&D projects are currently underway. These include domestic as well as international collaborations involving research institutions and waste management organizations from other countries. INER is involved in technology transfers, program integration, and consultation with SKB and Posiva based on granite host rock. TPC is involved in technical exchanges, annual meetings, and staff visits with NUMO (the nuclear waste management organization of Japan) and is preparing a memorandum of understanding with ANDRA (the French national agency for radioactive waste management).

\section{Research Activities of Advanced Fuel Cycles}

Various types of advanced fuel cycles are being developed around the world to achieve a sustainable supply of electricity, reduce the volume and radiotoxicity of SNF or HLW and improve resource utilization [25]. Most of these projects are based on partitioning and transmutation (P\&T) technologies, involving the conversion of radionuclides with long half-life, such as minor actinides (MAs), ${ }^{99} \mathrm{Tc}$, or ${ }^{129} \mathrm{I}$ in the fission products (FPs) into stable or shorter half-lives radioisotopes. The preliminary survey related to partitioning and transmutation (P\&T) technologies conducted between 2015 and 2016 focused on the international information collection, paper study and visiting some nuclear facilities in the European countries at INER.

The transmutation of MAs and FPs requires separation from HLW. Valuable elements in HLW can also be extracted, which has additional benefits of reducing the HLW volume in a scheme referred to as "partitioning". The HLW is categorized into four groups: (1) MAs, such as Am, Np and Cm; (2) platinum group metals (PGMs) such as Ru, Rh, and Pd for use as catalysts; (3) heating elements, such as $\mathrm{Sr}$ and Cs, for use as radiation sources; and (4) the remaining elements. Neither heat generating radionuclides nor long-lived alpha emitting ones are contained in the remaining elements, thereby allowing the space of the repository to be greatly reduced [25].

Following reprocessing, the MAs and FPs are the major nuclides in HLW. These compounds can have long-lasting effects on the human body. This radiotoxicity is dominated by MAs; therefore, these are the first targets of transmutation. Some long-lived FPs (LLFPs) are also important due to their high solubility in groundwater. These LLFPs play a critical role in the long-term safety assessment of final disposal based on the groundwater release scenario of the biosphere model [26].

The most common advanced technologies of nuclear reactors are Generation IV fast breeder reactors (FBR) and accelerator driven system (ADS). An ADS comprises a subcritical reactor connected to a particle (e.g., proton) accelerator. These advanced facilities have attracted considerable international research interests owing to their flexibility in burning $\mathrm{Pu}, \mathrm{MAs}$ and FPs. As a result, these facilities can greatly reduce the radiotoxicity of HLW by a factor of 100 [26].

Six systems [27] of advanced nuclear reactors were selected for the technology assessment of the R\&D roadmap and among these systems, the molten salt reactor (MSR) was chosen for research studies in Taiwan, as it was generally regarded as more self-sustainable of the next designs for the Generation-IV reactor with inherent properties of the safety system [28]. Compared to the current light-water reactor (LWR), the design of MSR is to improve safety, reduce costs and can transmute 
actinides in nuclear fuel and hydrogen production as one of the energy resources. The research on corrosion behavior of $\mathrm{Ni}$ - and Mo-based alloy structural material in the molten salt environment was also studied in the university [29]. The Netherlands' nuclear research and consultancy group (NRG) accomplished a significant milestone of irradiation test for MSR in its High Flux Reactor in September, 2019 [30]. However, the Generation IV program was turned down after the Fukushima nuclear accident in 2011. In addition, France dropped plans to construct a sodium-cooled fast-breeder reactor in August, 2019, because the disadvantage of liquid metal sodium in replace of water as a reactor coolant was its chemical reactivity and might result in serious safety concerns. The other reason was downward sloping prices of uranium for a decade [31].

As mentioned in the introduction, there are six units with a total power generation capacity of more than 5 GWe in Taiwan (Table 1). On average, 100-150 tons of SNF will be produced annually, namely yielding 100-150 kg of MAs per year. The total accumulated MAs for 40 years of operation is approximately 4-6 tons. In the case of a non-nuclear homeland after 2025, the amount of MAs produced in Taiwan is about $6800 \mathrm{~kg}$. If the EFIT-400 (European facility for industrial transmutation) for MAs of the EUROTRANS (the 6th framework program of EURATOM) program (2005-2010) is chosen, the transmutation rate is $35 \mathrm{~kg} / \mathrm{TWh}$ with a conceptual design of $400 \mathrm{MW}$ th for an ADS prototype. Therefore, the total energy and time for transmutation are 194 TWh (equal to $194 \times 10^{6} \mathrm{MWh}$ ) and about 485,000 hours (55.4 years) required to transmute the long-lived radioisotopes, respectively [32]. However, the choice of technology is assumed to have a relatively big impact on investment costs, which include the construction, operation, maintenance and fuel cycles and R\&D costs. Therefore, the other alternative is to adopt regional cooperation with other Asian countries, for example, Mainland of China, Japan or South Korea.

The Belgium nuclear research center (SCK•CEN) is actively engaging in developing a new multifunctional research facility: MYRRHA as in Multi-purpose hYbrid research reactor for high-tech applications [33]. INER signed a MoU (Memorandum of Understanding) with SCK•CEN in November 2016 [34]. The framework of this collaboration covers material research for fission reactors, reactor safety, fuel design, and the sub-critical core design of ADS engineering.

\section{Evaluation Results of Radiotoxicity vs. Timescale for Direct Disposal and Reprocessing of SNF}

The radioactivity (in $\mathrm{Ci}$ or $\mathrm{Bq}$ ) can be converted to radiotoxicity (in $\mathrm{Sv}$ ) by multiplying the dose conversion factor (DCF) for each radionuclide found in SNF and summing these together. The term of radiotoxicity is chosen as one of the appropriate safety indicators for underground SNF or HLW in different time periods for the safety assessment after closure of the repositories. As shown in Figure 5, after approximately 300,000 years, the radiotoxicity of SNF, based on the radionuclide inventories estimated with the ORIGEN-S computer code of the SCALE package (6.0, Oak Ridge National Laboratory, Oak Ridge, TN, USA) [35] and dose conversion factors of ICRP 119 [36] for typical BWR (boiling water reactor) fuel samples (2.66 \% initial enrichment), is comparable with that of the natural uranium ore once used to produce the fuel. Figure 5 also compares the time after discharge of radiological toxicity associated with SNF for direct disposal and HLW after reprocessing. The radiotoxicity level of $8 \mathrm{MtU}$ (metric ton unit) of natural uranium with daughters, which is commonly used to produce $1 \mathrm{MtU}$ of low-enriched uranium (LEU) fuel. The radiological toxicity of SNF decreases very slowly, such that it is not expected to drop below the level of the natural uranium for at least a few hundreds of thousands of years. HLW would require several thousand years to undergo the same process and shortens the time span to about 50,000 years. In the case of MAs transmutation, the time period further shortens down to approximately 300 years. The radiotoxicity trend as a function of time in this figure is much similar to those of literature [24,26]. Therefore, the P\&T technology is regarded as a good method of reducing the nuclear waste generation and the burden on the dry storage and final disposal in radioactive waste management size. 


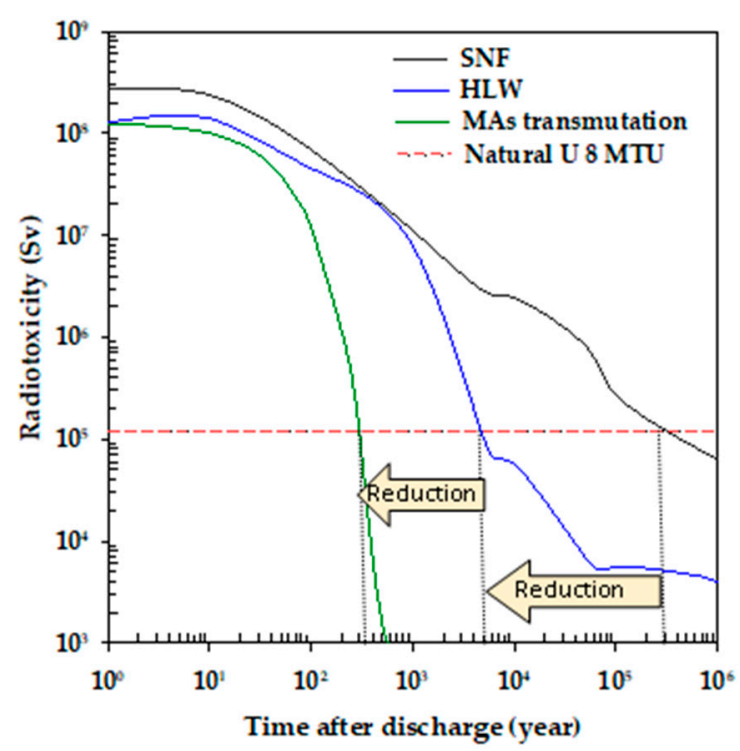

Figure 5. Reducing radiotoxicity profiles of SNF (solid black line), HLW (after reprocessing; solid blue line) and MAs transmutation (green line) in Taiwan.

\section{Conclusions and Future Outlook}

The wet storage, on-site dry storage and final disposal are short-term, mid-term and long-term strategies for SNF in Taiwan. The spent nuclear fuel pools of NPP1 and NPP2 will be fully loaded after permanent shutdown. To successfully carry out the decommissioning project, the dry storage facility is necessary, even though the obstacle from local government and residents is a predicament. According to the regulation, the decommissioning should be completely carried out within 25 years; however, the uncertainty of the interim storage and final disposal site will be a tough and political issue. Continuous communication with the public to build the consensus, legislation, amending the law and the construction of a centralized interim storage facility as an integrated waste management might be the possible solutions.

Based on the WANO (world association of nuclear operators) report, the nuclear power plants in Taiwan showed performance exceeding the goal for the past several years. Furthermore, a November 2018 referendum question showed approximately $60 \%$ support for maintaining the island's major dependence on nuclear power. As also shown in Table 1, the Maanshan nuclear power plant probably has the opportunity to apply for a 20-year life extension, which may make up for the energy gap, as the energy resources in Taiwan are very limited and more than $98 \%$ of the fuels are imported from foreign countries.

With respect to the advanced fuel cycles, the momentum of this research activity remains sluggish at the current stage. However, the R\&D cost focused on the enhancement of transmutation rate and the preliminary studies on the system of performance, safety, nuclear proliferation resistance, physical protection, reliability, sustainability and economics for ADS and MSR are needed in the future. It is worthwhile to seek regional-level or international cooperation along with the domestic program of ADS or propose a joint study on a Generation IV program in terms of the huge investment.

At present, for the utility, TPC is currently responsible for the operation and decommissioning of nuclear power plants and the dedicated agency, national radioactive waste management center will be in charge of implementing long-term management solutions of radioactive waste in the future. The management of SNF or HLW is a top priority of government, as the situation has become critical. The final disposal of SNF will have to be embraced to make Taiwan a nuclear-free homeland and prevent leaving the burden to future generations. This includes the development of technologies for site investigation and safety assessment, as well as construction activities. 
The SNF management is not only a technical issue but also a social one that needs much more time and patience to resolve the problem. Public support is a key issue in the selection of a final disposal site. Gaining public support will require public participation throughout the decision-making process and public acceptance can only be fostered by ensuring strict transparency in the dissemination of information pertaining to the advantages of this approach and the strategies that have been formulated.

Author Contributions: Conceptualization, T.-L.T.; methodology, T.-L.T.; software, S.-C.T.; validation, Y.-F.C.; formal analysis, Y.-F.C.; investigation, T.-L.T.; resources, Y.-F.C.; data curation, S.-C.T.; writing-original draft preparation, T.-L.T.; writing-review and editing, T.-L.T.; visualization, Y.-F.C.; supervision, S.-C.T.; project administration, T.-L.T.; funding acquisition, T.-L.T. All authors have read and agreed to the published version of the manuscript.

Funding: We thank Shian-Shing Shyu, the Institute Deputy Director-General and Chih-Hao Chen, the section head of Engineering Division for their expertise and assistance throughout all aspects of our study and for their help in responding the reviewers' comments on dry storage and revising the manuscript.

Acknowledgments: The authors would like to acknowledge the support granted by the Ministry of Science and Technology within the scope of the project with the reference MOST 109-3111-Y-042A-003.

Conflicts of Interest: The authors declare no conflict of interest.

\section{References}

1. Manabe, S. Role of greenhouse gas in climate change. Tellus A Dyn. Meteorol. Oceanogr. 2019, 74. [CrossRef]

2. IEA. Global Energy Review 2020: The Impacts of the Covid-19 Crisis on Global Energy Demand and CO2 Emissions; International Energy Association: Paris, France, 2020.

3. Mahmood, N.; Wang, Z.; Zhang, B. The role of nuclear energy in the correction of environmental pollution: Evidence from Pakistan. Nucl. Eng. Technol. 2020, 52, 1327-1333. [CrossRef]

4. Schneider, M.; Froggatt, A. The World Nuclear Industry Status Report; World Nuclear Association: London, UK, 2019.

5. Equinor ASA. Energy Perspectives 2019: Long-Term Macro and Market Outlook; Equinor ASA: Stavanger, Norway, 2019.

6. Kharecha, P.A.; Sato, M. Implications of energy and $\mathrm{CO}_{2}$ emission changes in Japan and Germany after the Fukushima accident. Energy Policy 2019, 132, 647-653. [CrossRef]

7. Rodríguez-Penalonga, L.; Moratilla-Soria, B.Y. A review of the nuclear fuel cycle strategies and the spent nuclear fuel management technologies. Energies 2017, 10, 1235. [CrossRef]

8. Department of Energy (DOE). Strategy for the Management and Disposal of Used Nuclear Fuel and High-Level Radioactive Waste; Department of Energy: Washington, DC, USA, 2013; pp. 3-14.

9. IAEA. Nuclear Energy Series No. NW-T-1.14 Status and Trends in Spent Fuel and Radioactive Waste Management; International Atomic Energy Agency: Vienna, Austria, 2018; pp. 20-38.

10. Taiwan Power Company. Current Status and Prospects of Chinshan and Kuosheng Nuclear Power Plant Decommissioning Programs; Taiwan Power Company: Taipei, Taiwan, 2017; pp. 11-13.

11. World Nuclear Association (WNA). Nuclear Power in Taiwan, July 2019. Available online: http://www. world-nuclear.org/information-library/country-profiles/others/nuclear-power-in-taiwan.aspx (accessed on 23 April 2020).

12. Atomic Energy Council (AEC). Spent Fuel Storage Status, April 2020. Available online: https://www.aec.gov. tw/english/radwaste/article301.php (accessed on 28 May 2020).

13. Huang, Y.H.; Lee, D.I. Technology Development for Dry Storage System of Spent Nuclear Fuels at INER, INER-3231; Institute of Nuclear Energy Research: Taoyuan, Taiwan, 2005; pp. 4-5.

14. Nuclear Safety NEA/CSNI/R (2017) 4. The Safety of Long-Term Interim Storage Facilities in NEA Member Countries; Organization for Economic Co-operation and Development (OECD)/Nuclear Energy Agency (NEA): Paris, France, 2017; pp. 15-67.

15. Pugliese, G.; Lo Frano, R.; Forasassi, G. Spent fuel transport cask thermal evaluation under normal and accident conditions. Nucl. Eng. Des. 2010, 240, 1699-1706. [CrossRef]

16. Lo Frano, R.; Pugliese, G.; Forasassi, G. Thermal analysis of a spent fuel cask in different transport conditions. Energy 2011, 36, 2285-2293. [CrossRef] 
17. IAEA Nuclear Energy Series No. NW-G-1.1. In Policies and Strategies for Radioactive Waste Management; International Atomic Energy Agency: Vienna, Austria, 2009; pp. 10-43.

18. Fuel Cycle and Materials Administration, Atomic Energy Council. Safety Management of Abroad Reprocessing Spent Nuclear Fuels. Available online: https://www.aec.gov.tw/english/radwaste/file/national_ report_20150303.pdf (accessed on 4 June 2020).

19. Huang, Y.H. Safety features of dry storage system at Chinshan nuclear power plant. In Infrastructure Systems for Nuclear Energy; Hsu, T.T.C., Wu, C.L., Li, J.L., Eds.; Wiley Online Library: New York, NY, USA, 2013; Chapter 30; pp. 504-505.

20. Atomic Energy Council (AEC). Dry Storage Management in Taiwan, February 2020. Available online: http://www.aec.gov.tw/english/radwaste/article05.php (accessed on 23 April 2020).

21. Liu, H.H. Current status of nuclear backend management in Taiwan. In Proceedings of the 3rd Taiwan-Japan Nuclear Experts Meeting, Taipei, Taiwan, 24 July 2019.

22. Survey of National Programs for Managing High-Level Radioactive Waste and Spent Nuclear Fuel: Update, A Report to Congress and the Secretary of Energy, U.S. Nuclear Waste Technical Review Board, February 2016. Available online: https://www.nwtrb.gov/docs/default-source/reports/survey_report_2016.pdf?sfvrsn=6 (accessed on 22 April 2020).

23. Taiwan Power Company. The Final Disposal Plan of Spent Nuclear Fuel, 2018 Revision (Chinese Edition); Taiwan Power Company: Taipei, Taiwan, 2019.

24. SKB. Long-term safety for the final repository for spent nuclear fuel at Forsmark. In Main Report of the SR-Site Project; TR-11-01; Svensk Kärnbränslehantering AB: Stockholm, Sweden, 2011; Volume 1.

25. Nishihara, K.; Nakayama, S.; Morita, Y.; Oigawa, H.; Iwasaki, T. Impact of partitioning and transmutation on LWR high-level waste disposal. J. Nucl. Sci. Technol. 2008, 45, 84-97. [CrossRef]

26. Oigawa, H. Transmutation of long-lived nuclear wastes. In Proceedings of the Conference on Advances in Radioactive Isotope Science (ARIS2014), Tokyo, Japan, 1-6 June 2014.

27. GIF R\&D Outlook for Generation IV Nuclear Energy Systems: 2018 Update. Available online: https://www. gen-4.org/gif/upload/docs/application/pdf/201906/7411_gif_r_and_d_outlook_update_web.pdf (accessed on 4 June 2020).

28. Serp, J.; Allibert, M.; Beneš, O.; Delpech, S.; Feynberg, O.; Ghetta, V.; Heuer, D.; Holcomb, D.; Ignatiev, V.; Kloosterman, J.L.; et al. The molten salt reactor (MSR) in generation IV: Overview and perspectives. Prog. Nucl. Energ. 2014, 77, 308-319. [CrossRef]

29. Lin, P.H. Corrosion Behaviors of Ni- and Mo-Based Alloys in High Temperature Molten Salt Environments (Chinese Edition). Master's Thesis, National Tsing Hua University, Hsin-Chu, Taiwan, 2017.

30. Major Molten Salt Nuclear Fuel Test Completed. Available online: https://newatlas.com/energy/majormolten-salt-nuclear-fuel-test-completed (accessed on 4 June 2020).

31. UPDATE 1-France Drops Plans to Build Sodium-Cooled Nuclear Reactor. Available online: https://af.reuters. com/article/energyOilNews/idAFL5N25Q3MS (accessed on 1 June 2020).

32. Chen, L.C.; Tsai, T.L.; Chiou, Y.F.; Shih, Y.F. The Final Report of the Feasibility Studies on Partitioning and Transmutation for Nuclear Wastes with Medium and Long Half-Lives; INER-PC-0326R; Institute of Nuclear Energy Research: Taoyuan, Taiwan, 2018; pp. 49-50.

33. SCK CEN. New Reactors and Fuels. 2020. Available online: https://www.sckcen.be/en/expertises/technology/ new-reactors-and-fuels (accessed on 23 April 2020).

34. Memorandum of Understanding between INER and SCK•CEN; CO-90-16-4196-00; Institute of Nuclear Energy Research, Atomic Energy Council: Taoyuan, Taiwan, 2016.

35. Oak Ridge National Laboratory (ORNL). SCALE: A Modular Code System for Performing Standardized Computer Analyses for Licensing Evaluation; ORNL/TM-2005/39, Version 6; Oak Ridge National Laboratory: Oak Ridge, TN, USA, 2009; Volume I-III, pp. 3-29.

36. ICRP Publication 119. Compendium of Dose Coefficients Based on ICRP Publication 60; ICRP Publication 119: Ottawa, ON, Canada, 2012; Volume 41, pp. 25-57.

(C) 2020 by the authors. Licensee MDPI, Basel, Switzerland. This article is an open access article distributed under the terms and conditions of the Creative Commons Attribution (CC BY) license (http://creativecommons.org/licenses/by/4.0/). 